\title{
Invasive Home Mechanical Ventilation: Living Conditions and Health-Related Quality of Life
}

\author{
Sophie Emilia Huttmann ${ }^{a}$ Wolfram Windisch ${ }^{a}$ Jan Hendrik Storre ${ }^{a, b}$ \\ ${ }^{a}$ Department of Pneumology, Cologne-Merheim Hospital, Kliniken der Stadt Köln, Witten-Herdecke University \\ Hospital, Cologne, and ${ }^{b}$ Department of Pneumology, University Medical Hospital, Freiburg, Germany
}

\section{Key Words}

Respiratory insufficiency · Health-related quality of life ·

Home mechanical ventilation · Tracheostomy

\begin{abstract}
Background: The number of patients with invasive home mechanical ventilation (HMV) following unsuccessful weaning is steadily increasing, but little is known about the living conditions and health-related quality of life ( $\mathrm{HRQL}$ ) in these patients. Objectives: To establish detailed information on living conditions and HRQL in patients with invasive HMV. Methods: The Severe Respiratory Insufficiency Questionnaire (SRI) was used to measure specific HRQL aspects in addition to patient interviews on individual living conditions during home visits. Results: Thirty-two patients with lung disease, most prominently COPD $(n=18)$, and neuromuscular disorders $(n=14)$ were included. The overall mean SRI summary scale score (range $0-100$ ) was $53 \pm 16$, with a broad range amongst individuals (23-86). Neuromuscular patients were younger than those with lung diseases ( $49 \pm 18$ vs. $67 \pm$ 11 years; $p<0.005$ ), and although they had a higher nursing dependency and fewer comorbidities, they tended to have higher (better) SRI summary scale scores (58 \pm 16 vs. $48 \pm 15$; $p=0.092$ ). Living in a private home compared to living in nursing facilities did not influence the SRI scores. Conclusions: Patients undergoing invasive HMV primarily following unsuccessful weaning reported an individual HRQL which,
\end{abstract}

when taken together, was highly heterogeneous and ranged from very good to extremely bad. Older patients with COPD and more comorbidities are likely to have a worse HRQL than neuromuscular patients, while the living situation does not influence the HRQL.

(c) 2015 S. Karger AG, Basel

\section{Introduction}

Health-related quality of life (HRQL) is an important outcome factor in patients with chronic, non-curable disorders. This is particularly pertinent to patients with severely advanced chronic respiratory failure who receive home mechanical ventilation (HMV) and in whom life expectancy is considerably reduced. When non-invasive ventilation (NIV) is used to administer HMV, the HRQL is reportedly improved in several disorders $[1,2]$.

In addition, HMV is increasingly being carried out with invasive forms of mechanical ventilation following tracheostomy [3]. In neuromuscular disorder (NMD) patients, invasive HMV is typically established when chronic respiratory failure deteriorates under NIV or when insufficient swallowing and secretion management require tracheostomy [4]. Here, the HRQL has been reported as acceptable according to some trials $[5,6]$. Furthermore, as the number of patients with chronic respiratory failure grows, invasive mechanical ventilation has become more

\section{KARGER 125}

2015 S. Karger AG, Base

$0025-7931 / 15 / 0894-0312 \$ 39.50 / 0$
Prof. Dr. Wolfram Windisch, MD

Department of Pneumology, Cologne-Merheim Hospital Kliniken der Stadt Köln, Witten-Herdecke University Hospital Ostmerheimer Strasse 200, DE-51109 Cologne (Germany)

E-Mail windischw@kliniken-koeln.de 
and more frequently necessary to treat acute on chronic respiratory failure in the ICU. These patients may eventually end up with invasive HMV, if weaning from mechanical ventilation proves unsuccessful [7-9]. Several factors that serve as predictors have been established for weaning failure, one of which is the underlying disease, such as COPD or NMD [9-11]. Patients with prolonged weaning are often treated in respiratory care units, and in many cases, end-of-life decision statements are not recorded [12]. As a consequence of unsuccessful weaning, patients are discharged with invasive HMV [7-9]. However, despite being a fundamentally important aspect of patient care, little remains known about the HRQL in patients. Indeed, detailed information about HRQL is suggested to (1) support patients in their end-of-life decision-making processes and (2) identify patients with severely reduced HRQL following the establishment of invasive HMV after unsuccessful weaning, since this group of patients would then need to be a target for further interventions aimed at improving their HRQL.

From this perspective, intensive care specialists constantly face the dilemma of whether to provide adequate life support to preserve a life with an extremely low HRQL when treating patients with chronic respiratory failure who are unlikely to be successfully weaned. Therefore, the present study aimed to investigate detailed and specific aspects of the HRQL in patients who were implemented with invasive HMV after acute respiratory failure had had to be managed in the ICU and in whom weaning from invasive mechanical ventilation was not feasible. In addition, this study also investigated whether the specific living conditions related to medical and nursing care had any influence on the HRQL in these patients.

\section{Methods}

The current study protocol was approved by the responsible ethics committee (Ethikkommission der Ärztekammer Nordrhein, Germany) and was performed in accordance with the ethical standards laid down in the Declaration of Helsinki, 2000. The study was registered at the German Clinical Trials Register (DRKS00005297). Informed written consent was obtained from all subjects or legal guardians.

\section{Subjects and Study Design}

The study was performed in adult patients with various underlying disorders that ultimately lead to severe chronic respiratory failure. All patients had been established on invasive HMV for at least 2 months prior to the study commencement. All patients were investigated during a stable phase of the disease when they were hospitalized for a planned routine check-up or when they were visited in their homes. In the latter case, the nursing facilities or nursing providers were contacted for support. Patients were only included if their participation was approved by the nursing care facility or nursing provider. Patients connected to our ventilation centre as well as outside patients were included. Patients with mental retardation or deafness were excluded.

The following information was collected from each patient: (1) primary disease leading to the chronic respiratory failure, (2) dependency on HMV, (3) further comorbidities, (4) living situation, (5) mechanical ventilation, (6) medical and nursing care and (7) supply of technical aids. In addition, the dependency on nursing care was estimated by assessing the Barthel Index of Activities of Daily Living, with lower values (range $0-100$ ) indicating higher disability $[13,14]$. The established nursing care level $(1=$ lowest; $3=$ highest $)$ according to the German nursing care insurance legislation [15] was recorded, where level 3 indicates extreme dependency on nursing care with need for assistance with basic care day and night.

Patients were asked to fill out the original German version of the Severe Respiratory Insufficiency Questionnaire (SRI) [16, 17]. If it was not possible for the patient to do this on his/her own, the SRI was answered via a structured interview. Here, all items were read out loud and answers were marked according to patient's statements. In order to maintain objectivity, 2 different investigators (Huttmann S. and Muth A.) randomly performed the interviews, while relatives were excluded from answering questions. Finally, patients were given an opportunity to express their perception of their quality of life as well as their individual attitude towards out-of-hospital invasive HMV. Here, key messages from each patient were derived from the interviews either through documentation of key citations or by describing the main observational issues.

\section{Severe Respiratory Insufficiency Questionnaire}

The SRI is an instrument specifically designed to measure the HRQL in patients with severe respiratory insufficiency. It contains 49 items with 7 subscales measuring different aspects of HRQL (Respiratory Complaints, Physical Functioning, Attendant Symptoms and Sleep, Social Relationships, Anxiety, Psychological Well-Being, Social Functioning). Each subscale produces a score (0-100), with lower scores indicating poorer health. The scales can be aggregated to 1 Summary Score. Answers are given on a 5-point Likert scale ranging between 'completely untrue' and 'always true'. So far, the SRI has been validated in several trials in patients with severe respiratory insufficiency while treated with long-term NIV $[1,2,16]$.

\section{Statistical Analysis}

All data derived from the SRI were subjected to normality testing using the Shapiro-Wilk test. Here, the whole group was tested in addition to subgroups. Group comparison was performed for (1) disease categories and (2) living situations. For disease categories, patients with NMD were compared to patients primarily suffering from lung diseases, the most relevant being COPD. For living situations, patients were categorized into those living in a private environment, i.e. in their own house or apartment, versus those living in nursing facilities. All normally distributed data are presented as means \pm standard deviation. Non-normally distributed data (Shapiro-Wilk with a p value of $<0.05$ ) are provided as median values with minimum and maximum values. For group comparison, paired $t$ tests were used for normally distributed data. A non-parametric test (Wilcoxon-Mann-Whitney rank sum test) was used on non-normally-distributed data. Group effects were 
estimated with $95 \%$ confidence intervals and tested with a 2 -sided level of 0.05 . For binary data on comorbidities, medical and nursing care and technical supply, Fisher's exact test was used comparing the proportions between different disease categories and living situations.

\section{Results}

\section{Patients}

A total of 32 patients receiving invasive HMV following tracheostomy were recruited between December 2013 and May 2014. Twelve patients were investigated during routine hospitalization, while 20 patients were visited at home. Demographic data and ventilator settings are given in table 1 . Another 3 patients who were invited to participate in the study declined to take part.

Advanced NMD was recorded in 14 patients as being the main cause of chronic respiratory failure and dependency on HMV (6 with amyotrophic lateral sclerosis (ALS), 3 with spinal cord injury, 2 with hereditary muscular metabolic diseases, 2 with Curschmann-Steinert myotonic dystrophy and 1 with Duchenne muscular dystrophy).

The remaining patients suffered from COPD $(n=11)$, overlap syndrome with COPD and coexisting obesity hypoventilation syndrome $(n=2)$ or destroyed lung $(n=1)$, while 4 patients suffered from chronic lung disease, which was not further classified; here, patients had multifactorial reasons for chronic respiratory failure with the primary cause not being identified clearly.

Demographics and ventilator characteristics are provided for NMD patients and those with chronic lung diseases in table 1. Two ALS patients and 1 patient with hereditary muscular metabolic disease started invasive mechanical ventilation during an acute worsening of their respiratory function, with tracheostomy having been approved by the patient during an earlier phase of stable disease. Of note, only 1 of these patients (ALS) had received NIV prior to the tracheostomy. In contrast, the remaining 29 patients had initially been intubated and treated in the ICU for acute respiratory failure, while invasive HMV was established following prolonged weaning and subsequent weaning failure. The distribution of chronic comorbidities is presented in figure 1.

\section{Living Situations and Data on Nursing and Medical Care}

Data on medical care, supply of technical aids for secretion management, mobilization and basic nursing
Table 1. Demographics and ventilator characteristics

\begin{tabular}{|c|c|c|c|}
\hline $\begin{array}{l}\text { Demographics and } \\
\text { ventilator settings }\end{array}$ & NMD & Lung disease & $\begin{array}{l}\mathrm{p} \\
\text { value }\end{array}$ \\
\hline Subjects, n & $14(100)$ & $18(100)$ & 1.0 \\
\hline Females, $\mathrm{n}$ & $6(43)$ & $11(61)$ & 0.476 \\
\hline Age, years & $49 \pm 18$ & $67 \pm 11$ & $<0.005$ \\
\hline $\begin{array}{l}\text { Duration of invasive } \\
\text { HMV, months }\end{array}$ & $\begin{array}{l}30 \pm 36^{\mathrm{a}} \\
19(3-132)\end{array}$ & $\begin{array}{l}21 \pm 20^{\mathrm{a}} \\
13(2-78)\end{array}$ & 0.775 \\
\hline IPAP, $\mathrm{cm} \mathrm{H}_{2} \mathrm{O}$ & $17 \pm 5$ & $25 \pm 8$ & $<0.001$ \\
\hline $\mathrm{EPAP}, \mathrm{cm} \mathrm{H}_{2} \mathrm{O}$ & $\begin{array}{l}5 \pm 2^{\mathrm{a}} \\
6(0-8)\end{array}$ & $\begin{array}{l}6 \pm 2^{\mathrm{a}} \\
5(4-10)\end{array}$ & 0.393 \\
\hline $\mathrm{RR}$, breaths/min & $\begin{array}{l}13 \pm 2^{\mathrm{a}} \\
13(10-16)\end{array}$ & $\begin{array}{l}16 \pm 3 \\
16(10-22)\end{array}$ & $<0.005$ \\
\hline $\begin{array}{l}\text { Spontaneous breathing, } \\
\text { hours/day }\end{array}$ & $\begin{array}{l}4 \pm 6^{\mathrm{a}} \\
1(0-16)\end{array}$ & $\begin{array}{l}6 \pm 7^{\mathrm{a}} \\
4(0-22)\end{array}$ & 0.393 \\
\hline LTOT, n & $6(43)$ & $18(100)$ & $<0.001$ \\
\hline LTOT, litres/min & $\begin{array}{l}1.9 \pm 1.0 \\
2.0(0.5-3.0)\end{array}$ & $\begin{array}{l}2.7 \pm 1.2^{\mathrm{a}} \\
2.5(1.0-6.0)\end{array}$ & 0.163 \\
\hline $\begin{array}{l}\text { NIV before invasive } \\
\text { HMV, n }\end{array}$ & $3(21)$ & $6(33)$ & 0.694 \\
\hline $\begin{array}{l}\text { Pre-agreement for } \\
\text { tracheostomy during } \\
\text { stable disease phase, } n\end{array}$ & $3(21)$ & $0(0)$ & 0.073 \\
\hline
\end{tabular}

Data are presented as absolute numbers with percentages in parentheses or as means \pm standard deviation with ranges in parentheses. EPAP = Expiratory positive airway pressure; IPAP = inspiratory positive airway pressure; LTOT = long-term oxygen therapy; $\mathrm{RR}=$ respiratory rate.

${ }^{a}$ For non-normally distributed data, median values with minimum and maximum in parentheses are also given.

care are provided in table 2 . Nineteen patients lived in a nursing facility together with other patients receiving invasive HMV (12 in a nursing home specialized for HMV and 7 in a community with an ambulatory nursing service caring for all patients within the community). Thirteen patients lived in their private homes and received support from an ambulatory nursing service. As a consequence, specialized nursing care was provided for all patients and was in accordance with the criteria set by the German Interdisciplinary Society of Home Mechanical Ventilation as outlined by recommendations and national guidelines $[18,19]$. Briefly, nurses caring for patients with invasive ventilation in the home environment were either trained as ICU nurses, had at least completed 
Table 2. Comparison of medical care, nursing care and supply of technical aids between patient groups (NMD versus lung diseases and private home versus nursing facility)

\begin{tabular}{|c|c|c|c|c|c|c|}
\hline & $\begin{array}{l}\text { NMD } \\
(n=14)\end{array}$ & $\begin{array}{l}\text { Lung disease } \\
(\mathrm{n}=18)\end{array}$ & $\begin{array}{l}\mathrm{p} \\
\text { value }\end{array}$ & $\begin{array}{l}\text { Private home } \\
(\mathrm{n}=13)\end{array}$ & $\begin{array}{l}\text { Nursing facility } \\
(\mathrm{n}=19)\end{array}$ & $\begin{array}{l}\mathrm{p} \\
\text { value }\end{array}$ \\
\hline Living situation/disease category & $\begin{array}{l}\text { Private home }(n=7) \\
\text { Nursing facility } \\
(n=7)\end{array}$ & $\begin{array}{l}\text { Private home }(\mathrm{n}=6) \\
\text { Nursing facility } \\
(\mathrm{n}=12)\end{array}$ & 0.473 & $\begin{array}{l}\text { NMD }(n=7) \\
\text { Lung disease } \\
(n=6)\end{array}$ & $\begin{array}{l}\operatorname{NMD}(\mathrm{n}=7) \\
\text { Lung disease } \\
(\mathrm{n}=12)\end{array}$ & 0.473 \\
\hline $\begin{array}{l}\text { Medical care } \\
\text { Connected to a ventilation centre } \\
\text { Home visit by family physician } \\
\text { Home visit by respiratory physician } \\
\text { Home visit by other medical specialist } \\
\text { Outpatient visits }\end{array}$ & $\begin{array}{r}9(64 \%) \\
13(93 \%) \\
7(50 \%) \\
9(64 \%) \\
2(14 \%)\end{array}$ & $\begin{array}{r}12(67 \%) \\
17(94 \%) \\
3(17 \%) \\
8(44 \%) \\
3(17 \%)\end{array}$ & $\begin{array}{l}1.0 \\
1.0 \\
0.062 \\
0.308 \\
1.0\end{array}$ & $\begin{array}{r}12(92 \%) \\
12(92 \%) \\
2(15 \%) \\
6(46 \%) \\
3(23 \%)\end{array}$ & $\begin{array}{r}9(47 \%) \\
18(95 \%) \\
8(42 \%) \\
11(58 \%) \\
2(11 \%)\end{array}$ & $\begin{array}{l}0.011 \\
1.0 \\
0.141 \\
0.720 \\
0.374\end{array}$ \\
\hline $\begin{array}{l}\text { Nursing care } \\
\text { Specialized nursing care } \\
\text { Relatives involved in nursing care } \\
\text { Nursing care insurance, level } 3 \\
\text { Barthel index }\end{array}$ & $\begin{aligned} & 14(100 \%) \\
& 5(36 \%) \\
& 12(86 \%) \\
& 24 \pm 24^{\mathrm{a}} ; 13(5-80)\end{aligned}$ & $\begin{array}{l}18(100 \%) \\
2(11 \%) \\
6(33 \%) \\
54 \pm 26 ; 58(5-95)\end{array}$ & $\begin{aligned} & 1.0 \\
& 0.195 \\
& 0.005 \\
&<0.005\end{aligned}$ & $\begin{array}{l}13(100 \%) \\
5(38 \%) \\
8(62 \%) \\
33 \pm 26\end{array}$ & $\begin{aligned} & 19(100 \%) \\
& 2(11 \%) \\
& 10(53 \%) \\
& 47 \pm 30\end{aligned}$ & $\begin{array}{l}1.0 \\
0.091 \\
0.725 \\
0.209\end{array}$ \\
\hline
\end{tabular}

Data are presented as absolute numbers and percentages in parentheses or as means \pm standard deviation with ranges in parentheses.

a For non-normally distributed data median values with minimum and maximum in parentheses are also given.

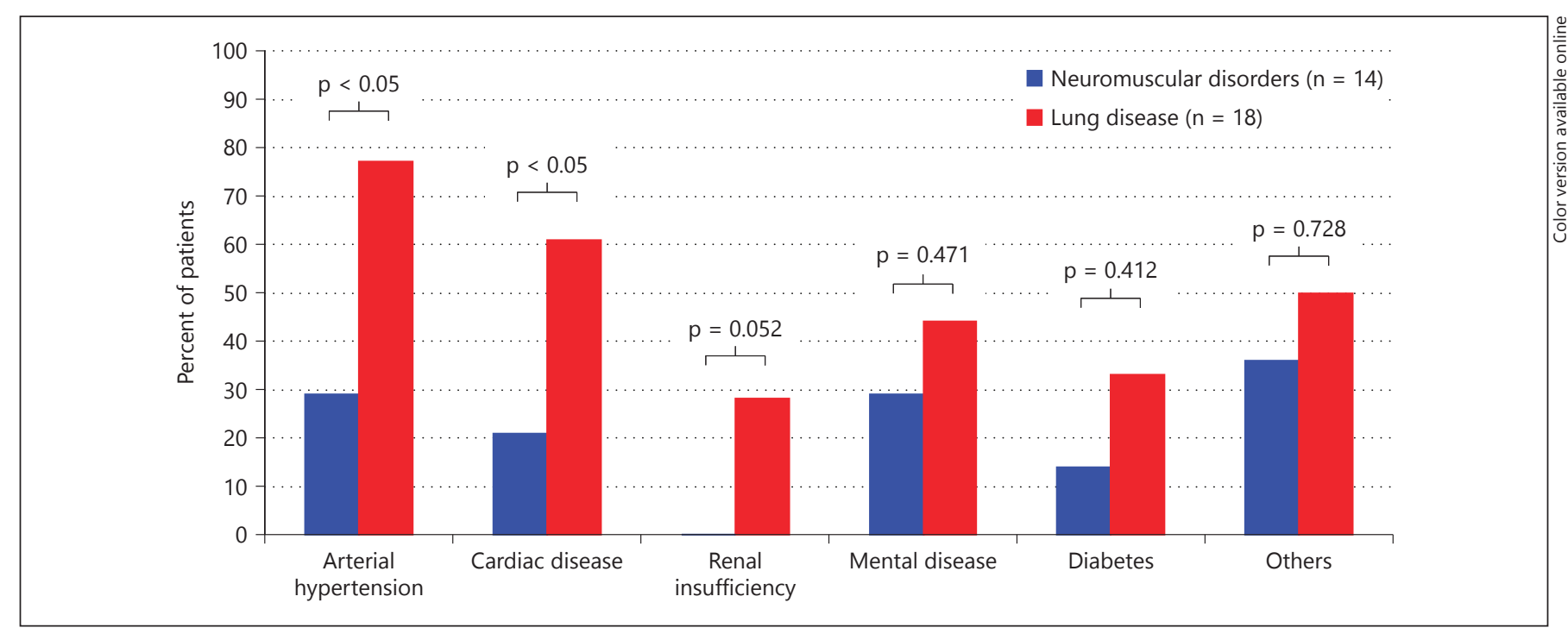

Fig. 1. Chronic comorbidities of patients receiving invasive HMV. Patients with neuromuscular disorders are compared to those with chronic lung diseases. The following comorbidities are summarized: arterial hypertension, cardiac diseases (coronary heart disease, disease of the cardiac valves, cardiac insufficiency and heart rhythm disorders), renal insufficiency (not dependent on dialysis), mental diseases (depression, chronic pain syndrome, anxiety disorder, personality disorder and claustrophobia), diabetes and other comorbidities (epilepsy, osteoporosis, peripheral arterial obstructive disease, hepatitis and hypothyroidism). 
Table 3. Subscales and summary scale of the SRI with respect to the underlying disease and living situation (NMD versus lung diseases and private home versus nursing facility)

\begin{tabular}{|c|c|c|c|c|c|c|}
\hline & $\begin{array}{l}\text { NMD } \\
(n=14)\end{array}$ & $\begin{array}{l}\text { Lung disease } \\
(\mathrm{n}=18)\end{array}$ & $\begin{array}{l}\mathrm{p} \\
\text { value }\end{array}$ & $\begin{array}{l}\text { Private home } \\
(\mathrm{n}=13)\end{array}$ & $\begin{array}{l}\text { Nursing facility } \\
(\mathrm{n}=19)\end{array}$ & $\begin{array}{l}\mathrm{p} \\
\text { value }\end{array}$ \\
\hline Living situation/disease category & $\begin{array}{l}\text { Private home } \\
(\mathrm{n}=7) \\
\text { Nursing facility } \\
(\mathrm{n}=7)\end{array}$ & $\begin{array}{l}\text { Private home }(\mathrm{n}=6) \\
\text { Nursing facility } \\
(\mathrm{n}=12)\end{array}$ & 0.473 & $\begin{array}{l}\text { NMD }(n=7) \\
\text { Lung disease } \\
(n=6)\end{array}$ & $\begin{array}{l}\text { NMD }(n=7) \\
\text { Lung disease } \\
(n=12)\end{array}$ & 0.473 \\
\hline Attendant Symptoms and Sleep & $70 \pm 18$ & $64 \pm 22$ & 0.389 & $69 \pm 18$ & $65 \pm 22$ & 0.552 \\
\hline Social Relationships & $69 \pm 16$ & $63 \pm 30$ & 0.703 & $71 \pm 29$ & $62 \pm 22$ & 0.301 \\
\hline Anxiety & $70 \pm 26$ & $53 \pm 28$ & 0.093 & $53 \pm 31$ & $65 \pm 26$ & 0.245 \\
\hline Psychological Well-Being & $58 \pm 28$ & $47 \pm 26$ & 0.259 & $55 \pm 31^{\mathrm{a}} ; 67(3-89)$ & $49 \pm 25 ; 42(6-92)$ & 0.589 \\
\hline Social Functioning & $52 \pm 23$ & $37 \pm 17$ & 0.039 & $48 \pm 24$ & $41 \pm 19$ & 0.385 \\
\hline
\end{tabular}

All data are presented as means \pm standard deviation.

a For non-normally distributed data, median values with minimum and maximum in parentheses are also given.

a German Interdisciplinary Society of Home Mechanical Ventilation-specialized nursing course or worked as a respiratory therapist.

Descriptive data for out-of-hospital medical and nursing care are illustrated in table 2. Sixty-six percent of all patients were connected to a ventilation centre for routine check-ups and possible emergency admissions at our centre or elsewhere. Specialized nursing was provided $24 \mathrm{~h}$ per day in 30 patients (94\%), while in 2 patients with relatives as additional carers, specialized nursing was provided for $10 \mathrm{~h}$ (ALS) and $16 \mathrm{~h}$ per day (hereditary muscular metabolic disease), respectively.

\section{Health-Related Quality of Life}

All patients completed the SRI (28 by interview and 4 by filling in the questionnaire themselves). Overall, the mean SRI summary score of $53 \pm 16$ was roughly in the middle of the possible scaling range. Following subgroup analysis, patients with NMD had higher SRI scores compared to lung disease patients, even though this was only statistically significant in the subscale 'social functioning' (table 3). There was no clear difference in HRQL between patients living in their private home compared to those who lived in nursing facilities (table 3).

There was a broad variety of individual SRI scores, and this was true for all subscales and, of note, also for the summary scale (fig. 2). Individual summary scale scores from all patients are listed in an ascending order in figure 3, documenting the broad variety of the SRI summary scale score across all patients. Key messages regarding individual life quality perception and living conditions are outlined in table 4 and presented in comparison to the SRI summary scale score for each patient. The mean values of the SRI scales of the NMD group are displayed in figure 4 and are presented in comparison to earlier data derived from 2 previous studies, in which the HRQL was assessed in patients with NMD receiving NIV $[1,20]$. Even though scores for physical functioning tended to be lower, while scores for anxieties tended to be higher in patients with invasive HMV, the overall HRQL as assessed by the SRI scale scores was nearly identical in patients with invasive compared to non-invasive HMV.

\section{Discussion}

This is the first study to provide detailed descriptions on patient characteristics, living conditions and specific aspects of HRQL in patients with long-term invasive HMV. The main finding was that specific aspects of HRQL were extremely heterogeneous across individual patients, with the reported HRQL ranging from poor to acceptable to very good. Another important finding was that patients with NMD tended to have higher HRQL 
Fig. 2. Individual subscale and summary scale scores from the SRI in patients with a neuromuscular disorders $(\mathrm{n}=14)$ and b lung diseases $(n=18)$ receiving invasive HMV. RC = Respiratory Complaints; PF = Physical Functioning; AS = Attendant Symptoms and Sleep; SR = Social Relationships; AX = Anxiety; WB = Psychological Well-Being; $\mathrm{SF}=$ Social Functioning; SS = Summary Scale.
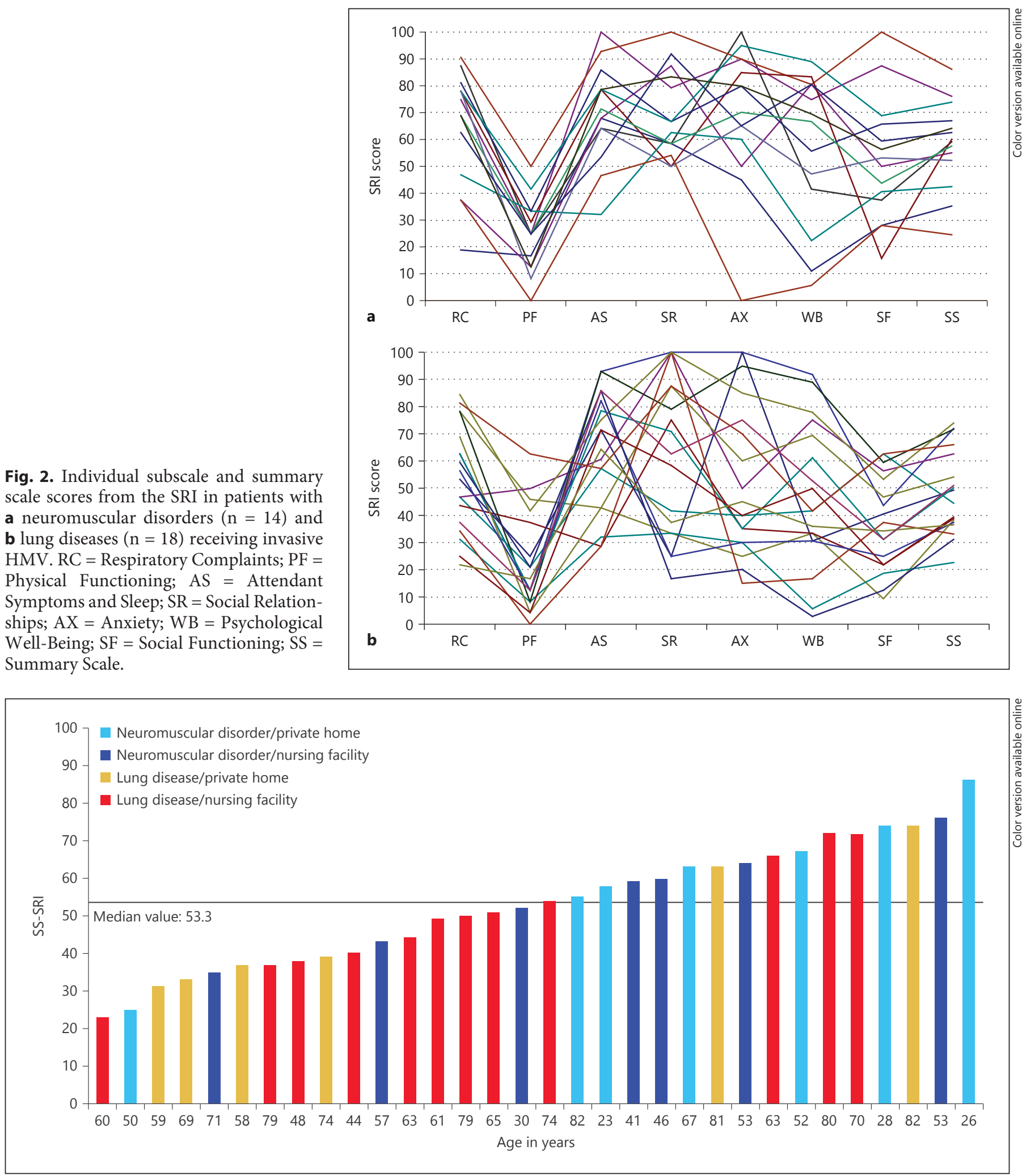

Fig. 3. Individual summary scale scores listed in ascending order from the SRI in patients receiving invasive HMV. Age, disease category (neuromuscular disorder or lung disease) and living situa- tion (private home or nursing facility) are illustrated for each patient. Additionally, the median value for all patients is presented. SS-SRI = Summary scale score of the SRI. 
Table 4. Individual key messages from patients receiving invasive HMV sorted by the summary scale score from the SRI $(\mathrm{n}=32)$

\begin{tabular}{|c|c|c|c|c|}
\hline Primary disease & $\begin{array}{l}\text { Age, } \\
\text { years }\end{array}$ & $\begin{array}{l}\text { Place of } \\
\text { residency }\end{array}$ & Subjective key message & SS-SRI \\
\hline Muscle dystrophy & 26 & $\mathrm{P}$ & Shares an apartment with brother and has many friends & 86 \\
\hline Muscle dystrophy & 53 & $\mathrm{~N}$ & Lives in firm partnership despite no verbal communication & 76 \\
\hline $\begin{array}{l}\text { Hereditary muscular } \\
\text { metabolic disease }\end{array}$ & 28 & $\mathrm{P}$ & $\begin{array}{l}\text { Has more desire for living again since HMV was started and wants to move to a } \\
\text { communal living setting }\end{array}$ & 74 \\
\hline Multifactorial & 80 & $\mathrm{~N}$ & 'I have no fear of dying soon' & 72 \\
\hline COPD & 70 & $\mathrm{~N}$ & $\begin{array}{l}\text { Despite being chronically bedridden, is in a positive state of mind because of good } \\
\text { social integration }\end{array}$ & 72 \\
\hline ALS & 52 & $\mathrm{P}$ & Is happy living with wife and son at home & 67 \\
\hline COPD & 81 & $\mathrm{P}$ & Is happy after having changed from nursing facility to private home 3 months ago & 63 \\
\hline ALS & 46 & $\mathrm{~N}$ & 'My greatest wish is to live with my family again' & 60 \\
\hline Muscle dystrophy & 41 & $\mathrm{~N}$ & 'I grew up with this disease, therefore, it's normal for me' & 59 \\
\hline ALS & 23 & $\mathrm{P}$ & Rapid disease progression, lives with family & 58 \\
\hline ALS & 82 & $\mathrm{P}$ & 'I can't use my hands, but I can use my computer for work' & 55 \\
\hline $\mathrm{COPD}+\mathrm{OHS}$ & 74 & $\mathrm{~N}$ & Receives frequent visits from family members and friends & 54 \\
\hline Spinal cord injury & 30 & $\mathrm{~N}$ & Has a strong Buddhist belief & 52 \\
\hline Destroyed lung & 44 & $\mathrm{~N}$ & 'All my other room-mates are in a coma except for me' & 40 \\
\hline COPD & 74 & $\mathrm{P}$ & 'I feel like a dog on leash' & 39 \\
\hline COPD & 48 & $\mathrm{~N}$ & 'The ventilator resembles something between a prison and a lifesaver' & 38 \\
\hline COPD & 58 & $\mathrm{P}$ & 'I will never get used to nurses living in our house' & 37 \\
\hline Multifactorial & 79 & $\mathrm{~N}$ & Can use the vacuum cleaner while being invasively ventilated & 37 \\
\hline ALS & 71 & $\mathrm{~N}$ & Regrets tracheostomy & 35 \\
\hline COPD & 69 & $\mathrm{P}$ & Repeatedly expresses the wish to die & 33 \\
\hline COPD & 59 & $\mathrm{P}$ & Does not want to be weaned, since nursing support can then be removed & 31 \\
\hline Spinal cord injury & 50 & $\mathrm{P}$ & 'I wish to have more of a social life' & 25 \\
\hline COPD & 60 & $\mathrm{~N}$ & Only non-verbal communication possible, no social contacts & 23 \\
\hline
\end{tabular}

ALS = Amyotrophic lateral sclerosis; COPD = chronic obstructive pulmonary disease; $\mathrm{OHS}=$ obesity hypoventilation syndrome; $\mathrm{N}=$ nurs ing facility; P = private home; SS-SRI = summary scale of the SRI. 
Fig. 4. Mean subscale and summary scale scores from the SRI in patients with neuromuscular disorders receiving invasive $\operatorname{HMV}(\mathrm{n}=14)$. Scores are displayed in parallel with earlier data derived from 2 previous studies in which patients with neuromuscular disorders received non-invasive HMV (Windisch et al. [1]: $\mathrm{n}=17$, Gosh et al. [20]: $\mathrm{n}=31)$. RC = Respiratory Complaints; PF = Physical Functioning; AS = Attendant Symptoms and Sleep; SR = Social Relationships; $\mathrm{AX}=$ Anxiety; $\mathrm{WB}=$ Psychological Well-Being; SF = Social Functioning; SS = Summary Scale.

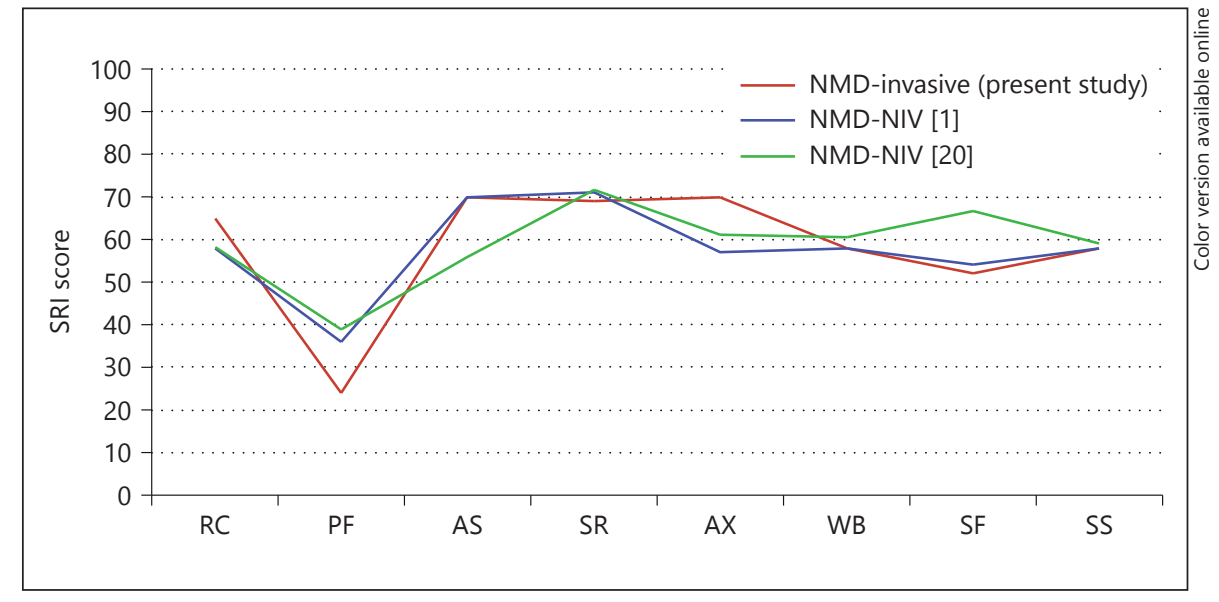

scores compared to patients primarily suffering from lung diseases. This is remarkable since NMD patients had the severest physical limitations and handicaps and, consequently, an increased dependency on nursing care. Apart from this, other conditions, particularly the living situation, had no influence on the HRQL.

HRQL has also previously been investigated in patients with invasive HMV. Overall, most of these studies compared patients with NIV and invasive HMV and found that the HRQL was not inferior in patients with invasive HMV $[5,6]$. Of note, most of these patients had neuromuscular or restrictive thoracic disorders, while half the patients in the present study primarily had chronic lung diseases. Another important difference is that the present study used the SRI, which specifically aims to assess the HRQL in patients with chronic respiratory failure receiving HMV $[16,17]$. In contrast, other studies primarily used generic instruments without employing validated questionnaires specific to chronic respiratory failure and HMV [5, 6]. Finally, nearly all patients in the present study received long-term invasive HMV after weaning failure. These differences might explain why the HRQL was severely reduced in at least some of the patients. Accordingly, a previous study reported a worsening of the clinical outcome in respiratory ICUs over the last few decades [7]. This is suggested to be the result of admitting to the respiratory centres more severely ill patients who had previously had a longer stay in the ICU as well as patients with a higher number of comorbidities. As a consequence, there is a growing number of invasive HMV patients, who are discharged with an ongoing need for ventilatory support. Therefore, the HRQL in this specific group of patients with significant comorbidities and weaning failure after an ICU stay (as in the present study)

Living Conditions and HRQL in Invasive HMV is likely to be reduced. This, in particular, held true for patients with chronic lung diseases, who were on average older and had more comorbidities than patients with NMD. Similarly, patients with long-term invasive HMV reportedly have lower survival rates if they suffer from lung diseases rather than neuromuscular disorders [4]. In the study by Marchese et al. [4], 90\% of all patients would choose tracheostomy and invasive HMV again, but the majority of patients had also been tracheotomized electively. Therefore, only a limited comparison of this result with the present data is possible. As a consequence, clinicians need to be aware of a potentially reduced HRQL when starting mechanical ventilation in the ICU in patients at risk for weaning failure [9-11].

On the other hand, a significant number of patients in this study reported a high HRQL, indicating that invasive HMV following weaning failure is not necessarily associated with a poor quality of life. In particular, NMD patients can have acceptable, subjectively reported mental health despite severe functional limitations, and this is similar to patients with long-term NIV $[21,22]$. In addition, the NMD patients with invasive HMV investigated here had SRI scores almost identical to those documented in earlier cohorts of NMD patients with NIV (fig. 4) [1, 20]. As an exception, anxieties tended to be less evident, although physical functioning was more impaired in NMD patients with invasive compared to earlier non-invasive HMV cohorts. Therefore, one could speculate that invasive $\mathrm{HMV}$ provides a sense of security at least in some severely disabled NMD patients with advanced chronic respiratory failure. Furthermore, patients with chronic respiratory failure following prolonged weaning (and also suffering from NMD), who were not dependent on HMV, had similar HRQL scores to patients with chronic 
respiratory failure who had electively received HMV in the form of long-term NIV [23].

Finally, previous work has also shown that generic aspects of HRQL are comparable between patients receiving invasive and non-invasive $\operatorname{HMV}[5,6]$. Therefore, there is now enough robust data to conclude that the HRQL in NMD patients is dependent on limitations caused by chronic respiratory failure and the underlying disease itself, rather than being caused by the type of ventilatory support.

Of note, $41 \%$ of the patients in this cohort lived in the same private homes where they had lived before invasive HMV was established, while $59 \%$ of the patients lived in nursing facilities. Patients living in a nursing facility were less frequently connected to a ventilation centre, but this was presumably biased by the fact that the majority of patients living at home were recruited via our hospital's databank. Nevertheless, the SRI scores were on average comparable, indicating that specific living conditions do not primarily influence the HRQL, as assessed by highly specific questionnaires. In addition, detailed interviews combined with visiting patients at home allowed the establishment of individual key messages about aspects of the HRQL, life perception and living conditions that are not even covered by specific questionnaires. Thereby it has been shown that the attitude towards specific individual living condition is complex and heterogeneous; some patients were satisfied with current living condition, while others were not, and this was true both for patients living in private homes and those living in nursing facilities.

Interestingly, a remarkable number of patients with NMD (43\%) were not only treated with mechanical ventilation but also with supplemental oxygen. One can assume that supplemental oxygen is not necessary in this subgroup if adequate secretion management is provided to these patients, e.g. with mechanical insufflator-exsufflators. Surprisingly, only a small number of patients with NMD were treated with specific secretion management (36\% in NMD and $11 \%$ in COPD, where these devices are usually not indicated). It remains unclear whether the application of supplemental oxygen was the consequence of inadequate secretion management.

There are some limitations of the study. Firstly, it is clear that the formulation of key messages was highly dependent on the investigator, with a possible lack of objectivity. However, these statements include important individual information on quality of life, in addition to highly objective and standardized HRQL measures, and are not aimed at replacing objective measures. Interestingly, positive and negative statements were associated with higher and lower SRI summary scale scores, respectively, supporting the value of additional subjective key messages. Secondly, it could be argued that there is a selection bias, since patients with reduced HRQL are not likely to have participated in the study. However, a broad spectrum of individual HRQL was uncovered by the study, and this was shown by both the SRI and the individual key messages. Thus, the spectrum of patients included here appears to be realistic. Thirdly, further studies are needed to provide a more systematic assessment of the HRQL in all patients discharged for invasive HMV, and this research also needs to include more detailed individual data on personal living conditions and attitudes towards life and death. This was not covered by the present study, but appears to be important as recent research has clearly demonstrated that the last phase of life in patients with $\mathrm{HMV}$ is associated with frequent problems and burdens related to both mechanical ventilation and the advanced stage of the disease; this was reportedly true for both patients and family members $[24,25]$.

In conclusion, living conditions, specific aspects of HRQL and individual attitudes towards personal living conditions all differed substantially within a group of patients receiving invasive HMV primarily following weaning failure. Overall, the HRQL is either good or poor based on individually evaluated conditions, even though older patients with lung diseases and more comorbidities are more likely to have a reduced HRQL compared to younger patients with neuromuscular disorders. More research is required in order to assess and define factors associated with reduced HRQL, particularly in the growing number of patients with lung diseases, comorbidities and weaning failure when recovering from ICU treatment.

\section{Acknowledgements}

We thank Axel Muth for his support in the patient interviews and Dr. Sandra Dieni, PhD, for her helpful comments on the manuscript prior to its submission.

\section{Financial Disclosure and Conflicts of Interest}

The study was supported by Weinmann Geräte für Medizin $\mathrm{GmbH} \& \mathrm{Co}$. KG and VIVISOL Deutschland GmbH. All authors state that none of the discussed issues in the submitted manuscript was dependent on, or influenced by, support and funding.

All authors received speaking fees and travel funding from companies which are involved in mechanical ventilation. 


\section{References}

1 Windisch W: Impact of home mechanical ventilation on health-related quality of life. Eur Respir J 2008;32:1328-1336.

2 Windisch W: Home Mechanical Ventilation; in Tobin MJ (ed): Principles and Practice of Mechanical Ventilation, ed 3. New York, McGraw-Hill, 2012, pp 001-016.

$>3$ Lloyd-Owen SJ, Donaldson GC, Ambrosino N, Escarabill J, Farre R, Fauroux B, Robert D, Schoenhofer B, Simonds AK, Wedzicha JA: Patterns of home mechanical ventilation use in Europe: results from the Eurovent survey. Eur Respir J 2005;25:1025-1031.

$\checkmark 4$ Marchese S, Lo Coco D, Lo Coco A: Outcomes and attitudes toward home tracheostomy ventilation of consecutive patients: a 10 year experience. Respir Med 2008;102:430436.

5 Kaub-Wittemer D, von Steinbuchel N, Wasner M, Laier-Groeneveld G, Borasio GD: Quality of life and psychosocial issues in ventilated patients with amyotrophic lateral sclerosis and their caregivers. J Pain Symptom Manage 2003;26:890-896.

6 Markström A, Sundell K, Lysdahl M, Andersson G, Schedin U, Klang B: Quality-of-life evaluation of patients with neuromuscular and skeletal diseases treated with noninvasive and invasive home mechanical ventilation. Chest 2002;122:1695-1700.

-7 Polverino E, Nava S, Ferrer M, Ceriana P, Clini E, Spada E, Zanotti E, Trianni L, Barbano L, Fracchia C, Balbi B, Vitacca M: Patients' characterization, hospital course and clinical outcomes in five Italian respiratory intensive care units. Intensive Care Med 2010;36:137142.

8 Schönhofer B, Euteneuer S, Nava S, Suchi S, Köhler D: Survival of mechanically ventilated patients admitted to a specialised weaning centre. Intensive Care Med 2002;28:908-916. $\checkmark 9$ Boles JM, Bion J, Connors A, Herridge M, Marsh B, Melot C, Pearl R, Silverman H, Stanchina M, Vieillard-Baron A, Welte T: Weaning from mechanical ventilation. Eur Respir J 2007;29:1033-1056.

10 Hannan LM, Tan S, Hopkinson K, Marchingo E, Rautela L, Detering K, Berlowitz DJ, McDonald CF, Howard ME: Inpatient and long-term outcomes of individuals admitted for weaning from mechanical ventilation at a specialized ventilation weaning unit. Respirology 2013;18:154-160.

11 Sellares J, Ferrer M, Cano E, Loureiro H, Valencia M, Torres A: Predictors of prolonged weaning and survival during ventilator weaning in a respiratory ICU. Intensive Care Med 2011;37:775-784.

-12 Nava S, Sturani C, Hartl S, Magni G, Ciontu M, Corrado A, Simonds A: End-of-life decision-making in respiratory intermediate care units: a European survey. Eur Respir J 2007; 30:156-164.

13 Barthel Activities of Daily Living (ADL) Index. Occas Pap R Coll Gen Pract 1993;59:24.

14 Wade DT, Collin C: The Barthel ADL Index: a standard measure of physical disability? Int Disabil Stud 1988;10:64-67.

15 Soziale Pflegeversicherung, Stufen der Pflegebedürftigkeit, § 15 Absatz 1 SGB XI (last amended by Art. 2a G v. 15.7.2013 I 2423).

16 Windisch W, Freidel K, Schucher B, Baumann H, Wiebel M, Matthys H, Petermann F: The Severe Respiratory Insufficiency (SRI) Questionnaire: a specific measure of healthrelated quality of life in patients receiving home mechanical ventilation. J Clin Epidemiol 2003;56:752-759.

17 Windisch W, Budweiser S, Heinemann F, Pfeifer M, Rzehak P: The Severe Respiratory Insufficiency (SRI) Questionnaire was valid for patients with COPD. J Clin Epidemiol 2008;61:848-853.

$>18$ Randerath WJ, Kamps N, Brambring J, Gerhard F, Lorenz J, Rudolf F, Rosseau S, Scheumann A, Vollmer V, Windisch W: Recommendations for invasive home mechanical ventilation. Pneumologie 2011;65:72-88.
19 Windisch W, Brambring J, Budweiser S, Dellweg D, Geiseler J, Gerhard F, Köhnlein T, Mellies U, Schönhofer B, Schucher B, Siemon $\mathrm{K}$, Walterspacher S, Winterholler M, Sitter $\mathrm{H}$ : Non-invasive and invasive mechanical ventilation for treatment of chronic respiratory failure. S2-Guidelines published by the German Medical Association of Pneumology and Ventilatory Support (in German). Pneumologie 2010;64:207-240.

20 Gosh D, Rzehak P, Elliott MW, Windisch W Validation of the English Severe Respiratory Insufficiency Questionnaire. Eur Respir J 2012;40:408-415.

21 Windisch W, Freidel K, Schucher B, Baumann H, Wiebel M, Matthys H, Petermann F: Evaluation of health-related quality of life using the MOS 36-Item Short-Form Health Status Survey in patients receiving noninvasive positive pressure ventilation. Intensive Care Med 2003;29:615-621.

22 Kohler M, Clarenbach CF, Böni L, Brack T, Russi EW, Bloch KE: Quality of life, physical disability, and respiratory impairment in Duchenne muscular dystrophy. Am J Respir Crit Care Med 2005;172:1032-1036.

-23 Euteneuer S, Windisch W, Suchia S, Köhler D, Jones PW, Schönhofer B: Health-related quality of life in patients with chronic respiratory failure after long-term mechanical ventilation. Respir Med 2006;100:477-486.

24 Vitacca M, Grassi M, Barbano L, Galavotti G, Sturani C, Vianello A, Zanotti E, Ballerin L, Potena A, Scala R, Peratoner A, Ceriana P, Di Buono L, Clini E, Ambrosino N, Hill N, Nava S: Last 3 months of life in home-ventilated patients: the family perception. Eur Respir J 2010;35:1064-1071.

25 Windisch W: Home mechanical ventilation: who cares about how patients die? Eur Respir J 2010;35:955-957. 